\title{
Adubação nitrogenada associada à inoculação com Azospirillum brasilense e Herbaspirillum seropedicae na cultura do milho ${ }^{1}$
}

\author{
Janaína Dartora $^{2}$, Vandeir F. Guimarães ${ }^{3}$, Deniele Marini ${ }^{4}$ \& Gerson Sander ${ }^{4}$
}

\begin{abstract}
RESUMO
Bactérias dos gêneros Azospirillum e Herbaspirillum são fixadoras de nitrogênio (N) atmosférico e consideradas promotoras do crescimento vegetal. Desta forma, desenvolveu-se o presente trabalho com o objetivo de avaliar o desenvolvimento e a produtividade do milho em resposta à inoculação de $A$. brasilense e $H$. seropedicae associada à adubação nitrogenada. $\mathrm{O}$ experimento foi conduzido em delineamento experimental de blocos ao acaso em esquema fatorial $4 \times 5$, com quatro repetições. Os tratamentos foram constituídos da inoculação de sementes (testemunha, estirpe de $A$. brasilense - Ab-V5, estirpe de H. seropedicae - SmR1 e combinação Ab-V5 + SmR1) e doses de N (0, 40, 80, 120 e $160 \mathrm{~kg} \mathrm{ha}^{-1}$ de N). Foram avaliados: diâmetro basal do colmo, altura de planta, matéria seca de parte aérea e área foliar, nas fases vegetativa e reprodutiva, e produtividade. A adubação nitrogenada favoreceu o desenvolvimento da cultura até a máxima dose estudada. A inoculação combinada das estirpes proporcionou incrementos de $12 \%$ na matéria seca de parte aérea e $7 \%$ na produtividade em relação à testemunha indicando benefícios da combinação de bactérias diazotróficas que interagem de forma diferenciada com a planta.
\end{abstract}

Palavras-chave: Zea mays L., bactérias diazotróficas, fitohormônios

\section{Nitrogen fertilization associated to inoculation with Azospirillum brasilense and Herbaspirillum seropedicae in the maize}

\begin{abstract}
Bacteria of the genera Azospirillum and Herbaspirillum have the ability to fix atmospheric nitrogen $(\mathrm{N})$ and promote plant growth. The aim of this study was to evaluate the development and productivity of maize in response to inoculation with $A$. brasilense and $H$. seropedicae associated to $\mathrm{N}$ fertilizer. The experimental design was a randomized complete block with four replications and treatments arranged in a $4 \times 5$ factorial. The treatments consisted of inoculation of seeds (control, strain of A. brasilense - Ab-V5, strain of H. seropedicae -SmR1 and combination SmR1+Ab-V5) and N levels (0, 40, 80, 120 and 160 $\mathrm{kg} \mathrm{N} \mathrm{ha}^{-1}$ ). The basal diameter of stem, plant height, shoot dry weight and leaf area were evaluated at the vegetative and reproductive stages, and productivity. Nitrogen fertilization promoted the development of the crop until maximum nitrogen dose studied. The combined inoculation of strains of $A$. brasilense (Ab-V5) and $H$. seropedicae (SmR1) provided increments of $12 \%$ dry weight of shoot and $7 \%$ in grain yield compared to the control, indicating benefits of the combination of diazotrophic bacteria that interact differently with the plant.
\end{abstract}

Key words: Zea mays L., diazotrophs, phytohormones

Parte da Dissertação de Mestrado do primeiro autor apresentada ao Programa de Pós-Graduação em Agronomia UNIOESTE

${ }^{2}$ Doutoranda em Agronomia/UNIOESTE, Rua Pernambuco, 1777, C. P. 91, CEP 85960-000, Marechal Cândido Rondon, PR. Fone: (45) 3284-7911.

E-mail: janaina_dartora@yahoo.com.br

${ }^{3}$ Departamento de Agronomia/UNIOESTE. Fone: (45) 3284-7911. E-mail: vandeirfg@yahoo.com.br

${ }^{4}$ Mestre em Agronomia/UNIOESTE. E-mail: denielemarini@yahoo.com.br; gerson_sander@hotmail.com 


\section{INTRODUÇÃO}

O milho (Zea mays L.) é o principal cereal cultivado no Brasil. Na safra 2011/2012 cerca de 15,4 milhões de hectares foram cultivados com a cultura no país, com produtividade média de $4.265 \mathrm{~kg} \mathrm{ha}^{-1}$ havendo uma perspectiva global de aumento na demanda e no preço do produto (CONAB, 2012).

Embora apresente elevada taxa fotossintética, o milho é uma cultura muito influenciada por problemas de estresse ambiental dentre os quais se destacam aqueles relacionados à baixa fertilidade dos solos. $\mathrm{O}$ nitrogênio $(\mathrm{N})$ constitui componentes essenciais da célula vegetal sendo considerado um nutriente fundamental envolvido no incremento da produtividade das culturas; entretanto, os solos brasileiros apresentam, em sua maioria, baixo teor de $\mathrm{N}$ disponível tornando a adubação nitrogenada uma prática indispensável e, neste contexto, os fertilizantes inorgânicos se destacam como a principal forma de adição do nutriente ao solo.

Considerando o elevado custo econômico e ambiental do processo industrial de fixação de $\mathrm{N}$ aliado ao aumento da demanda por alimentos, surge a necessidade de se incorporar, à atividade agrícola, novas tecnologias que visem à racionalização do uso de fertilizantes nitrogenados. Uma alternativa é o aproveitamento dos benefícios proporcionados pela associação entre bactérias diazotróficas (fixadoras de $\mathrm{N}$ ) e culturas de grande interesse econômico visto que tais micro-organismos são capazes de promover o crescimento vegetal e gerar incrementos no desenvolvimento e na produtividade das culturas (Baldani et al., 1997).

No Brasil, estudos pioneiros com bactérias diazotróficas associadas a gramíneas têm apresentado grande diversidade de micro-organismos isolados de diversas culturas destacando-se, para a cultura do milho, bactérias dos gêneros Azospirillum e Herbaspirillum. Micro-organismos do gênero Azospirillum são denominados diazotrofos endofíticos facultativos (Döbereiner \& Baldani, 1982) uma vez que colonizam tanto o interior quanto a superfície das raízes, enquanto Herbaspirillum spp. constituem diazotrofos endofíticos obrigatórios apresentando baixa sobrevivência no solo (Baldani et al., 1997).

Ensaios desenvolvidos pela Embrapa Soja testando diferentes estirpes de $A$. brasilense e A. lipoferum nas culturas do milho e do trigo demonstraram que a inoculação com A. brasilense proporcionou incrementos de 24 a $30 \%$ no rendimento de grãos da cultura do milho em relação ao controle sem inoculação resultando na identificação das primeiras estirpes autorizadas para a produção de inoculantes comerciais no Brasil (Hungria et al., 2010). Dotto et al. (2010) verificaram que a inoculação com $H$. seropedicae resultou em incremento de $8,6 \%$ na produtividade do milho. No entanto, a existência de certo grau de especificidade de algumas bactérias diazotróficas em relação ao hospedeiro torna o genótipo da planta um fatorchave na obtenção dos benefícios oriundos da associação planta-bactéria (Reis et al., 2000).

Estudos com a inoculação combinada de estirpes de Azospirillum e Herbaspirillum não têm sido relatados e necessitam ser explorados, assim como sua associação com doses de N. Neste sentido, o presente estudo teve como objetivo avaliar o desenvolvimento e a produtividade da cultura do milho em resposta à inoculação de $A$. brasilense e $H$. seropedicae em associação à adubação nitrogenada.

\section{Material e Métodos}

O experimento foi conduzido na safra verão 2010/2011 em semeadura direta no município de Marechal Cândido Rondon, PR ( $54^{\circ} 22^{\prime} \mathrm{W} ; 24^{\circ} 46^{\prime} \mathrm{S}$ e altitude de $420 \mathrm{~m}$ ). Os dados de precipitação pluviométrica e as temperaturas mínimas, máximas e médias mensais incidentes durante a realização do experimento são apresentados na Figura 1.

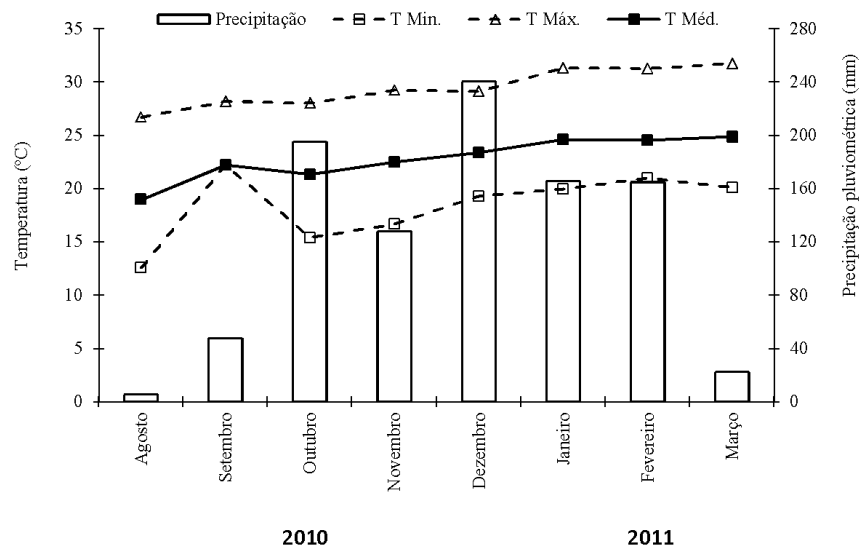

Figura 1. Precipitação pluviométrica acumulada e temperatura mínima, máxima e média mensal no período de agosto/2010 a março/2011

O solo é classificado como Latossolo Vermelho distróférrico com textura argilosa cujas características químicas na camada 0-20 cm foram: $\mathrm{pH}\left(\mathrm{CaCl}_{3}\right), 5,5 ; \mathrm{P}, 18,34 \mathrm{mg} \mathrm{dm}^{-3} ; \mathrm{K}, 0,2 \mathrm{cmol}_{\mathrm{c}}$ $\mathrm{dm}^{-3}$; matéria orgânica, $34,18 \mathrm{~g} \mathrm{dm}^{-3} ; \mathrm{Al}, 0,27 \mathrm{cmol}_{\mathrm{c}} \mathrm{dm}^{-3} ; \mathrm{Ca}$, $2,92 \mathrm{cmol}_{\mathrm{c}} \mathrm{dm}^{-3} ; \mathrm{Mg}, 1,52 \mathrm{cmol}_{\mathrm{c}} \mathrm{dm}^{-3}$; CTC 11,84 $\mathrm{cmol}_{\mathrm{c}} \mathrm{dm}^{-3}$; $\mathrm{V} \%$ 49,5; H $+\mathrm{A} 17,19 \mathrm{cmol}_{\mathrm{c}} \mathrm{dm}^{-3}$.

$\mathrm{O}$ delineamento experimental empregado foi em blocos casualizados em esquema fatorial $4 \times 5$, com quatro repetições, sendo o primeiro fator referente à inoculação das sementes com bactérias diazotróficas: tratamento sem inoculação (testemunha), estirpe de $A$. brasilense (Ab-V5), estirpe de $H$. seropedicae (SmR1) e combinação das duas estirpes (Ab-V5 + SmR1); o segundo fator compreendeu as doses de adubo nitrogenado em estudo: $0,40,80,120$ e $160 \mathrm{~kg} \mathrm{ha}^{-1}$ de N.

Os inoculantes foram fornecidos pela Universidade Federal do Paraná (UFPR) sendo preparados a partir de uma solução de bactérias pura na concentração de $1 \times 10^{9} \mathrm{UFC} \mathrm{mL}^{-1}$. A inoculação com as bactérias $A$. brasilense e $H$. seropedicae foi realizada antes da semeadura, através da mistura das sementes ao inoculante em uma proporção de $1 \mathrm{~mL}$ de inoculante para 1.000 sementes sendo que, no caso da inoculação combinada das estirpes, foi utilizada metade desta proporção de inoculante $(0,5 \mathrm{~mL})$ de cada estirpe totalizando, assim, a mesma proporção de $1 \mathrm{~mL}$ para 1.000 sementes.

A semeadura foi realizada com auxílio de matracas, no dia 06/10/2010, utilizando-se o híbrido simples 30R50 Hercule $^{\circledR}$. Cada unidade experimental constou de seis linhas com $5 \mathrm{~m}$ de comprimento, espaçadas entre si 0,70 $\mathrm{m}$ sendo distribuídas cinco plantas por metro. $\mathrm{Na}$ adubação 
de semeadura foram aplicados $40 \mathrm{~kg} \mathrm{ha}^{-1}$ de $\mathrm{P}_{2} \mathrm{O}_{5}, 50 \mathrm{~kg}$ $\mathrm{ha}^{-1}$ de $\mathrm{K}_{2} \mathrm{O}$ e $30 \mathrm{~kg} \mathrm{ha}^{-1}$ de $\mathrm{N}$ suspendendo-se a adubação nitrogenada para os tratamentos sem N. O restante da dose de N, conforme os tratamentos estabelecidos foi aplicado em cobertura entre os estádios V4 e V6 utilizando como fonte de $\mathrm{N}$ a ureia $(46 \%$ de $\mathrm{N})$. Como fontes de fósforo e potássio foram utilizados superfosfato triplo $\left(42 \%\right.$ de $\left.\mathrm{P}_{2} \mathrm{O}_{5}\right)$ e cloreto de potássio $\left(58 \%\right.$ de $\left.\mathrm{K}_{2} \mathrm{O}\right)$ respectivamente.

Durante a condução do experimento foi realizada uma aplicação de herbicidas antes do fechamento da cultura utilizando-se uma mistura de herbicidas seletivos para a cultura do milho com os ingredientes ativos triazine $(5,0 \mathrm{~L}$ $\left.\mathrm{ha}^{-1}\right)$ e nicosulfuron $\left(1,5 \mathrm{~L} \mathrm{ha}^{-1}\right)$. Realizaram-se, também, duas aplicações de inseticida, aos 18 e 30 dias após a semeadura utilizando-se produto contendo tiametoxam + lambdacialotrina como ingredientes ativos $\left(0,25 \mathrm{~L} \mathrm{ha}^{-1}\right)$.

As coletas de plantas para avaliação das variáveis biométricas foram realizadas nas fases vegetativa (V8) e reprodutiva (R3) da cultura retirando-se, de forma aleatória, duas plantas por parcela dentro da área útil. As avaliações foram feitas em campo quanto à altura e diâmetro basal do colmo, com auxílio de régua e paquímetro digital, respectivamente; em seguida, as plantas foram seccionadas em diferentes partes (folhas, colmo + bainha e espigas), acondicionadas em sacos de papel, identificadas e levadas à estufa de circulação forçada de ar a $65 \pm 2{ }^{\circ} \mathrm{C}$ por $72 \mathrm{~h}$, para posterior pesagem e determinação da matéria seca. A área foliar foi determinada pelo método da massa seca de discos foliares através da retirada de amostras e da relação entre massa seca da área do disco com a massa seca da folha.

A colheita do milho foi realizada manualmente, no dia 15/03/11, coletando-se todas as espigas da parcela útil constituída de duas linhas centrais de $3 \mathrm{~m}$ cada uma para determinação da produtividade em $\mathrm{kg} \mathrm{ha}^{-1}$ após a correção da umidade dos grãos para $13 \%$ (base úmida).

Os dados foram submetidos à análise de variância pelo programa SISVAR (Ferreira, 2008) e as médias comparadas pelo teste Tukey $(\mathrm{p} \leq 0,05)$; no caso das respostas das variáveis em função das doses de $\mathrm{N}$ foi utilizada análise de regressão pelo teste $\mathrm{t}$ de Student.

\section{Resultados E Discussão}

Não se verificou interação significativa entre a inoculação de $A$. brasilense e $H$. seropedicae com a adubação nitrogenada para as características avaliadas (Tabela 1); desta forma, os resultados são apresentados independentemente para os fatores inoculação e adubação nitrogenada.

A altura de planta não foi influenciada pela inoculação com A. brasilense e $H$. seropedicae nas duas fases de avaliação tendo-se observado valores médios de 141,7 e $246,6 \mathrm{~cm}$ nas fases vegetativa e reprodutiva, respectivamente (Tabela 2). Lana et al. (2012) também não verificaram, avaliando as respostas da cultura do milho à inoculação com Azospirillum associada à adubação nitrogenada, efeito da inoculação sobre a altura de planta.

Houve efeito da inoculação sobre o diâmetro basal do colmo nas fases vegetativa e reprodutiva (Tabela 2). A combinação das estirpes Ab-V5 e SmR1 proporcionou maior diâmetro basal do colmo em relação à testemunha, em ambas as fases de avaliação, embora sem diferir das estirpes inoculadas de forma isolada na fase vegetativa e da estirpe Ab-V5 na fase reprodutiva. $\mathrm{Na}$ fase vegetativa $\mathrm{o}$ incremento proporcionado pela inoculação combinada das estirpes no diâmetro basal do colmo em relação à testemunha foi de $15 \%$ e pode ser associado ao efeito de promoção do crescimento proporcionado pelas

Tabela 1. Análise de variância para altura (ALT), diâmetro basal do colmo (DC), matéria seca de parte aérea (MSPA) e área foliar $(\mathrm{AF})$, nas fases vegetativa $(\mathrm{V})$ e reprodutiva $(\mathrm{R})$ e produtividade de grãos (PROD) da cultura do milho, híbrido 30R50, em função da inoculação com estirpes de $A$. brasilense (Ab-V5) e H. seropedicae (SmR1) de forma isolada e combinada, associada à adubação nitrogenada

\begin{tabular}{|c|c|c|c|c|c|c|c|c|c|c|}
\hline \multirow{2}{*}{ F.V. } & \multirow{2}{*}{ G.L. } & \multicolumn{9}{|c|}{ Quadrados médios } \\
\hline & & ALT V & ALT R & DC V & DC R & MSPA V & MSPA R & AF V & AF $R$ & PROD \\
\hline Inoc (I) & 3 & 76,3 & 4,3 & $78,6^{\star *}$ & $12,9 * \star$ & 8185035 & $175413242^{*}$ & 99,4 & 53,9 & 4103749 \\
\hline IXN & 12 & 71,2 & 81,5 & 21,1 & 2,0 & 3911366 & 31472858 & 52,3 & 258,9 & 1313974 \\
\hline Resíduo & 57 & 181,1 & 60,8 & 15,9 & 2,8 & 3454579 & 47396083 & 64,1 & 193,0 & 1805781 \\
\hline C.V. (\%) & & 9,5 & 3,2 & 12,3 & 6,3 & 14,4 & 15,3 & 14,4 & 25,1 & 13,8 \\
\hline
\end{tabular}

*, ** Significativos a 0,05 e 0,01 de probabilidade pelo teste $\mathrm{F}$, respectivamente

Tabela 2. Altura (ALT), diâmetro basal do colmo (DC, mm), matéria seca de parte aérea (MSPA) e área foliar (AF), nas fases vegetativa $(\mathrm{V})$ e reprodutiva (R) e produtividade de grãos (PROD) da cultura do milho, híbrido 30R50, em função da inoculação com estirpes de A. brasilense (Ab-V5) e H. seropedicae (SmR1) de forma isolada e combinada

\begin{tabular}{|c|c|c|c|c|c|c|c|c|c|}
\hline \multirow{2}{*}{ Bactéria } & \multicolumn{2}{|c|}{ ALT (cm) } & \multicolumn{2}{|c|}{$\mathrm{DC}(\mathrm{mm})$} & \multicolumn{2}{|c|}{ MSPA (kg ha-1) } & \multicolumn{2}{|c|}{ AF (dm² planta $\left.{ }^{-1}\right)$} & \multirow{2}{*}{$\begin{array}{c}\text { PROD } \\
\left(\mathrm{kg} \mathrm{ha}^{-1}\right)\end{array}$} \\
\hline & V & $\mathbf{R}$ & V & $\mathbf{R}$ & $\mathbf{V}$ & $\mathbf{R}$ & V & $R$ & \\
\hline Ab-V5 & 141,9 & 247,1 & $31,9 a b$ & $26 \mathrm{~b}$ & $6.258,4$ & $10.527,8 b$ & 53,0 & 54,7 & 10536,5 \\
\hline$A b-V 5+S m R 1$ & 139,2 & 246,2 & $35,1 \mathrm{a}$ & $28 \mathrm{a}$ & $6.825,9$ & $12.032,9 \mathrm{a}$ & 57,6 & 57,0 & 11573,1 \\
\hline Média & 141,7 & 246,6 & 32,4 & 27 & $6.446,0$ & $11.269,6$ & 55,7 & 55,4 & 10916,4 \\
\hline C.V. $(\%)$ & 9,5 & 3,2 & 12,3 & 6,33 & 14,4 & 15,3 & 14,4 & 25,1 & 12,77 \\
\hline
\end{tabular}

Médias seguidas da mesma letra na coluna não diferem significativamente entre si pelo teste de Tukey, $p<0,05$ 
bactérias diazotróficas. Ao contrário do presente estudo, Dotto et al. (2010) não verificaram, avaliando a inoculação de $H$. seropedicae e níveis de $\mathrm{N}$ sobre o comportamento de híbridos de milho, efeito da inoculação sobre o diâmetro de colmo das plantas de milho.

Não foi constatado efeito da inoculação para a matéria seca da parte aérea na fase vegetativa enquanto na fase reprodutiva a combinação das estirpes diferiu significativamente da inoculação isolada de Ab-V5 (Tabela 2). Embora sem diferir estatisticamente da testemunha na fase reprodutiva a inoculação combinada das estirpes proporcionou incremento de $12 \%$ na matéria seca da parte aérea em relação à testemunha. Quadros (2009) observou, avaliando o desempenho agronômico de híbridos de milho inoculados com Azospirillum em associação com a adubação nitrogenada, incrementos ainda superiores, de até 53\%, no rendimento da matéria seca da parte aérea para o tratamento inoculado em relação ao tratamento controle evidenciando o efeito benéfico da inoculação.

Os incrementos verificados no diâmetro basal do colmo e no acúmulo de matéria seca das plantas submetidas à inoculação podem ser associados à produção de fito-hormônios pelas bactérias, como auxinas, giberelinas e citocininas (Radwan et al., 2004; Moreira et al., 2010). Segundo Okon \& LabanderaGonzalez (1994) este efeito de promoção do crescimento é notável visto que esses micro-organismos estimulam a densidade e o comprimento de pelos radiculares assim como a taxa de aparecimento de raízes laterais resultando em aumento na superfície de contato radicular (Radwan et al., 2004) o que potencializa o aproveitamento de água e nutrientes disponíveis no solo (Baldani et al., 1997).

Quanto à área foliar não foi verificado efeito significativo da inoculação com bactérias diazotróficas em ambas as fases de avaliação apresentando valores médios de 55,7 e $55,4 \mathrm{dm}^{2}$ por planta nas fases vegetativa e reprodutiva, respectivamente (Tabela 2).

Não houve efeito significativo da inoculação para a produtividade de grãos cuja média foi de $10.916 \mathrm{~kg} \mathrm{ha}^{-1}$ (Tabela 2). É relevante salientar que a elevada produtividade alcançada neste estudo, mesmo sem adubação nitrogenada em cobertura, é consequência de um conjunto de fatores favoráveis ao desenvolvimento da cultura, como o elevado potencial produtivo do híbrido utilizado, o elevado teor de matéria orgânica no solo e a incidência de condições climáticas favoráveis durante a condução do experimento, conforme observado na Figura 1.

Embora a produtividade não tenha sido influenciada pela inoculação, observa-se que o tratamento submetidoà inoculação combinada das estirpes Ab-V5 e SmR1 proporcionou incremento de $922 \mathrm{~kg} \mathrm{ha}^{-1}$ em relação à testemunha, o que representa um ganho de 15 sacas a mais por hectare cultivado sugerindo a aplicabilidade da inoculação para o cultivo do milho. Estudos realizados até o momento têm relatado efeito benéfico da inoculação com Azospirillum ou Herbaspirillum à cultura do milho. Quadros (2009) observou que a inoculação pode suprir parte do nitrogênio necessário à cultura pois a adição de $50 \mathrm{~kg} \mathrm{ha}^{-1}$ de $\mathrm{N}$ associados à inoculação de $A$. brasilense apresentou desempenho equivalente à aplicação de
$130 \mathrm{~kg} \mathrm{ha}^{-1}$ de N quanto ao rendimento de grãos. Bartchechen et al. (2010) verificaram, em estudo com inoculante comercial à base de $A$. brasilense associado a diferentes doses de $\mathrm{N}$, que a inoculação proporcionou resultados superiores de produtividade do milho em relação à testemunha porém não houve diferenças na produtividade com a inoculação isolada ou associada à adubação nitrogenada em cobertura. Lana et al. (2012) confirmaram os efeitos benéficos da inoculação obtendo incrementos de 7 a $15 \%$ na produtividade do milho em função da inoculação.

A resposta positiva das plantas à inoculação com bactérias diazotróficas pode ser atribuída a outros fatores, além da produção de substâncias promotoras do crescimento, tais como proteção contra fitopatógenos, alteração da atividade metabólica através de efeitos sobre as membranas celulares (Bashan et al., 2004), solubilização de fosfatos, aumento da resistência das plantas ao estresse e a própria fixação biológica de nitrogênio (Gray \& Smith, 2005). No entanto, apesar das vantagens que as bactérias diazotróficas proporcionam às plantas sua eficiência é prejudicada, muitas vezes, em função de estarem associadas livremente à planta, seja na rizosfera ou no interior dos tecidos, tornando-se muito vulneráveis ao ambiente (Gyaneshwar et al., 2002); assim como o genótipo da planta hospedeira (Reis et al., 2000; Iniguez et al., 2004) as características do solo têm sido frequentemente associadas à ausência de resposta à inoculação (Dobbelaere et al., 2002).

Considerando que a atividade e a sobrevivência da comunidade bacteriana do solo sofre influência de diversos fatores ambientais, como temperatura, umidade, competição com micro-organismos do solo etc. (Brandão, 1992) infere-se que a interação de $H$. seropedicae com as plantas tenha sido fundamental para obtenção de respostas positivas à inoculação combinada de estirpes haja vista que, apesar de sua contribuição como bactéria promotora do crescimento vegetal ser considerada menor em relação a outras espécies (Moreira et al., 2010), H. seropedicae, diazotrofo endofítico obrigatório, sobrevive pouco no solo e coloniza nichos específicos no interior dos tecidos vegetais tornando mais eficiente a transferência dos compostos nitrogenados produzidos para a planta (Olivares, 1997). Além de que, através desta relação mais íntima com a planta, a bactéria se torna menos vulnerável ao ambiente externo e se encontra livre de limitações de substratos de carbono (Olivares, 1997) e da competição com outros microorganismos edáficos (Moreira et al., 2010).

A. brasilense, bactéria predominantemente rizosférica, contribuiu de forma menos expressiva para os resultados da inoculação combinada em relação a $H$. seropedicae, uma vez que é mais vulnerável a estresses ambientais e pode ter sido influenciada pelo próprio $\mathrm{pH}$ do solo nas condições de estudo (Tabela 1) embora não tenham sido realizadas contagens bacterianas de solo e planta para sustentar esta afirmação. É notável que, apesar de o pH do solo $(5,5)$ se encontrar dentro da faixa considerada adequada para a cultura do milho $(5,5 \mathrm{a}$ $6,5)$, está abaixo da faixa considerada ideal $(6,0$ a 6,5$)$ para a máxima atividade microbiana no solo (Coelho \& Verlengia, 1973). Segundo Brandão (1992) sob valores extremos de pH o crescimento de micro-organismos do solo pode ser prejudicado não apenas pelo efeito direto da elevada concentração de íons $\mathrm{H}^{+}$ 
e $\mathrm{OH}^{-}$mas também pela influência indireta na disponibilidade de nutrientes e na penetração de compostos tóxicos presentes no meio no interior das células microbianas.

Verificou-se efeito significativo da adubação nitrogenada quanto à altura da planta em ambas as fases de avaliação (Figura 2). $\mathrm{Na}$ fase vegetativa constatou-se ajuste significativo ( $\mathrm{p} \leq$ 0,05 ) dos dados a um modelo polinomial quadrático (Figura 2A) que permitiu estimar a altura máxima de planta $(147,42$ $\mathrm{cm})$ que seria obtida teoricamente com a dose de $118 \mathrm{~kg} \mathrm{ha}^{-1} \mathrm{de}$ N. Na fase reprodutiva os dados se ajustaram ao modelo linear crescente $(\mathrm{p} \leq 0,01)$ em função das doses de N (Figura 2B) sendo observado incremento de $0,05 \mathrm{~cm}$ na altura de planta para cada $\mathrm{kg}$ de $\mathrm{N}$ adicionado ao solo. Lana et al. (2012) não verificaram diferenças na altura de planta com as doses de $\mathrm{N}$ testadas na cultura do milho atribuindo tal resultado às características genéticas dos híbridos em estudo.

$\mathrm{O}$ incremento na altura de plantas observado neste estudo está associado ao alongamento do caule promovido pelo $\mathrm{N}$ devido ao fato de que, segundo Marschner (1995) a aplicação

A.

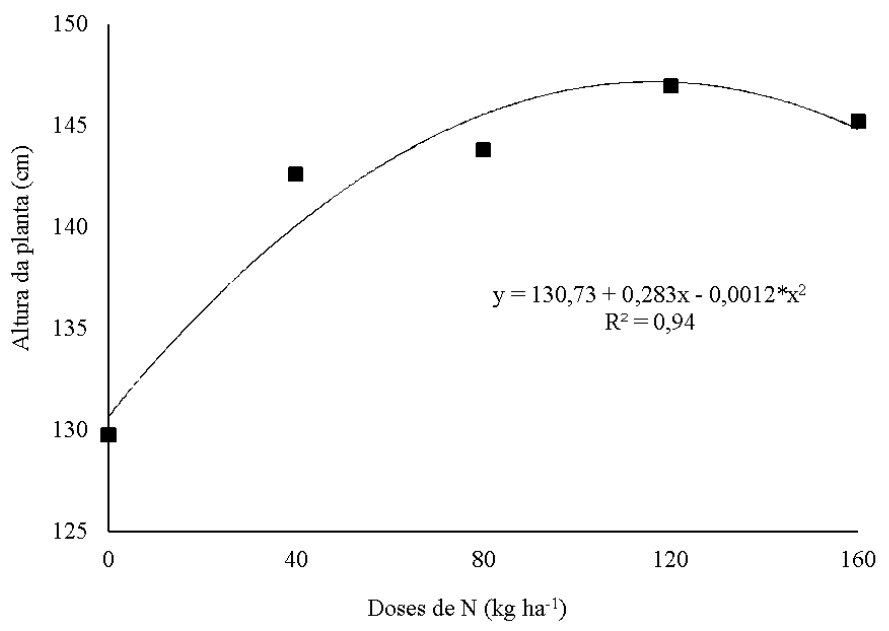

de doses elevadas de $\mathrm{N}$ nos estádios iniciais de desenvolvimento dos cereais promove aumento da produção de fito-hormônios promotores do crescimento (auxinas, giberilinas e citocininas) responsáveis pelos processos de divisão e expansão celular.

A adubação nitrogenada influenciou positivamente o diâmetro basal do colmo das plantas de milho apenas na fase reprodutiva observando-se ajuste linear crescente $(p \leq 0,01)$ dos dados e acréscimo de $0,009 \mathrm{~mm}$ no diâmetro para cada $\mathrm{kg}$ de $\mathrm{N}$ adicionado ao solo ( $\left.\mathrm{y}=25,8656+0,0091 * * \mathrm{x}, \mathrm{R}^{2}=0,54\right)$. Resultado contrário obtiveram Lucena et al. (2000) avaliando o efeito de doses de fósforo e $\mathrm{N}$ sobre a cultura do milho pois os autores não constataram efeito do $\mathrm{N}$ sobre o diâmetro do colmo das plantas. Cabe salientar que maior diâmetro do colmo está diretamente relacionado com o aumento da produção, uma vez que atua no armazenamento de sólidos solúveis que serão utilizados posteriormente para a formação dos grãos (Fancelli \& Dourado Neto, 2000) especialmente se algum estresse vier a comprometer a taxa de produção e translocação de fotoassimilados durante a fase de enchimento de grãos.

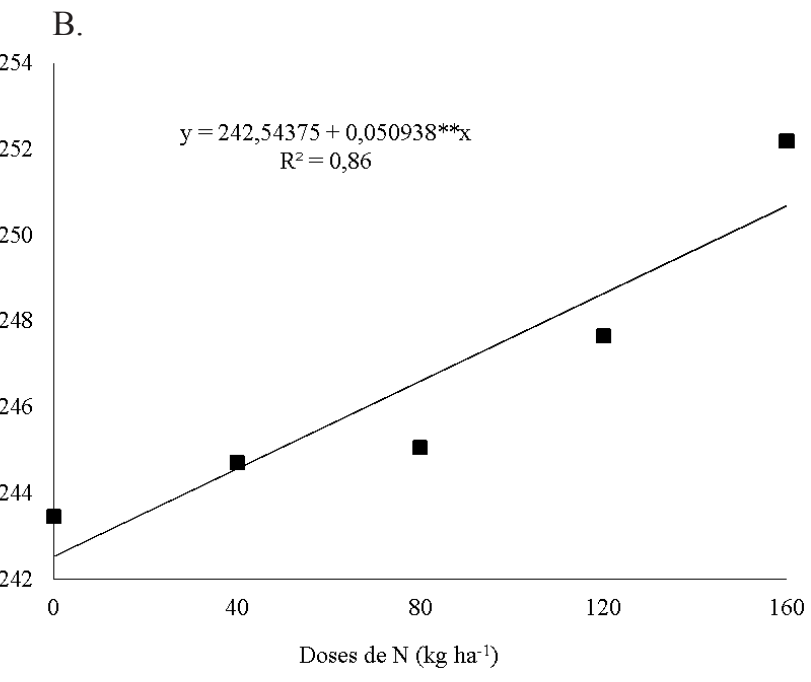

*, ** Significativo pelo teste T de Student $p \leq 0,05$ e $p \leq 0,01$, respectivamente

Figura 2. Altura de planta nas fases vegetativa (A) e reprodutiva (B), da cultura do milho, híbrido 30R50, em função da adubação nitrogenada

A.

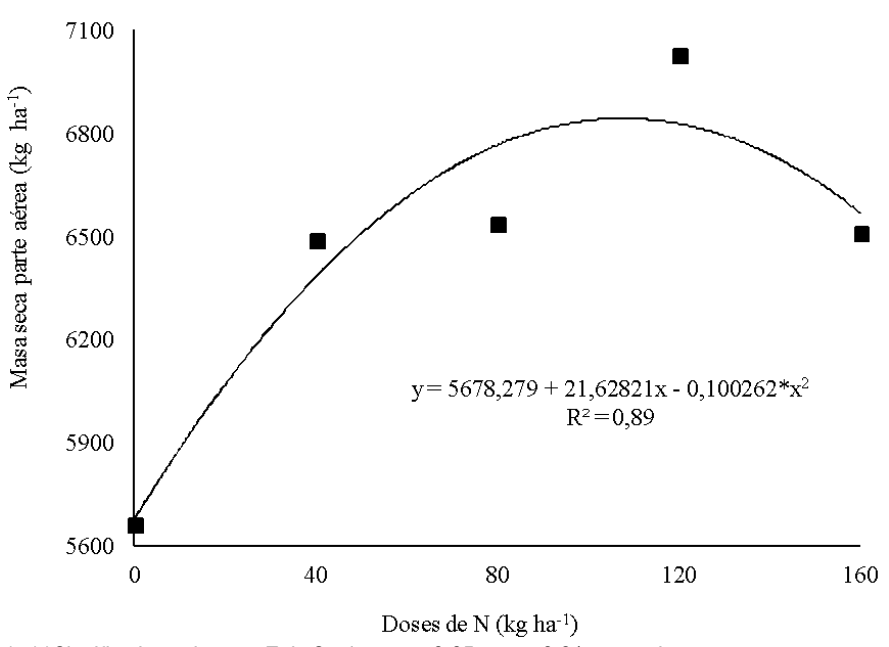

B.

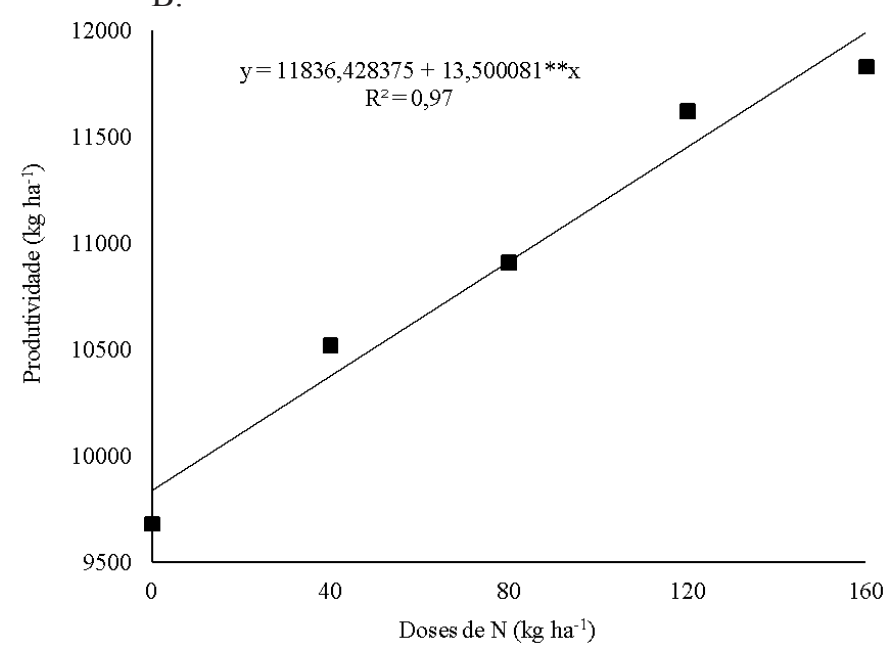

, ${ }^{*}$ Significativo pelo teste $T$ de Student $p \leq 0,05$ e $p \leq 0,01$ respectivamente

Figura 3. Matéria seca da parte aérea na fase vegetativa (A) e produtividade de grãos da cultura do milho, híbrido 30R50, em função da adubação nitrogenada 
Ocorreu influência da adubação nitrogenada sobre a matéria seca de parte aérea nas fases vegetativa e reprodutiva. A curva de resposta da variação da matéria seca de parte aérea na fase vegetativa em função das doses de $\mathrm{N}$ aplicadas ao solo (Figura $3 \mathrm{~A})$ apresentou efeito polinomial quadrático $(\mathrm{p} \leq 0,05) \mathrm{com}$ máxima produção de matéria seca da parte aérea $\left(6.845 \mathrm{~kg} \mathrm{ha}^{-1}\right)$ para a dose de $108 \mathrm{~kg} \mathrm{ha}^{-1}$ de $\mathrm{N}$; já na fase reprodutiva não houve ajuste dos dados; quanto à área foliar houve influência da adubação nitrogenada apenas na fase reprodutiva, porém também não foi possível ajuste.

Para a produtividade de grãos de milho verificou-se ajuste linear crescente dos dados $(p \leq 0,01)$ em função da adubação nitrogenada (Figura 3B), com incremento de 13,5 kg $\mathrm{ha}^{-1}$ no rendimento da cultura para cada quilo de $\mathrm{N}$ adicionado ao solo. Duete et al. (2008) também constataram incremento na produtividade em função da adubação nitrogenada obtendo incremento na produtividade de grãos até a dose de $175 \mathrm{~kg}$ $\mathrm{ha}^{-1}$ de N.

$\mathrm{O}$ estímulo proporcionado pela adubação nitrogenada no desenvolvimento da planta como um todo é devido ao fato do $\mathrm{N}$ estar intimamente ligado ao processo de crescimento da planta participando da constituição de proteínas, enzimas, coenzimas, ácidos nucleicos, fitocromos, pigmentos fotossintéticos etc. (Büll, 1993). Além disto, o $\mathrm{N}$ favorece o crescimento do sistema radicular propiciando, à planta, condições para maior absorção de água e nutrientes (Rao et al., 1992). Assim, o crescimento da planta é favorecido e, consequentemente, promove aumento da área fotossinteticamente ativa da planta e síntese de fotoassimilados, que são translocados para os grãos (Büll, 1993) proporcionando incremento na produtividade.

\section{Conclusões}

1. Nas condições de estudo não se observou influência das doses de $\mathrm{N}$ sobre as bactérias diazotróficas.

2. A aplicação de doses crescentes de $\mathrm{N}$ em cobertura, proporcionou incremento no desenvolvimento da planta e produtividade de grãos até a dose de $160 \mathrm{~kg} \mathrm{ha}^{-1}$ de N, confirmando os benefícios do nitrogênio às plantas.

3. A inoculação combinada das estirpes de $A$. brasilense e $H$. seropedicae proporcionou melhor desenvolvimento da cultura do milho em relação à testemunha em função da interação diferenciada das bactérias com a planta proporcionando incrementos no diâmetro basal do colmo, matéria seca de parte aérea e produtividade de grãos.

\section{Agradecimentos}

À Fundação Araucária de Apoio ao Desenvolvimento Científico e Tecnológico do Paraná, afiliada à Secretaria de Estado da Ciência, Tecnologia e Ensino Superior - SETI; $\mathrm{CAPES} / \mathrm{PNPD}$ e ao CNPq/INCT pelo suporte financeiro.

\section{Literatura Citada}

Baldani, J. I.; Caruso, L.; Baldani, V. L. D.; Goi, S. R.; Dobereiner J. Recent advances in BNF with non-legume plants. Soil Biology and Biochemistry, v.29, p.911-922, 1997.
Bartchechen, A.; Fiori, C. C. L.; Watanabe, S. H.; Guarido, R. C. Efeito da inoculação de Azospirillum brasiliense na produtividade da cultura do milho (Zea mays L.). Campo Digital, v.5, p.56-59, 2010.

Bashan, Y.; Holguin, G.; Bashan, L. E. de. Azospirillum-plant relationships: physiological, molecular, agricultural, and environmental advances (1997-2003). Canadian Journal of Microbiology, v.50, p.521-577, 2004.

Brandão, E. M. Os componentes da comunidade microbiana do solo. In: Cardoso, E. J. B. N.; Tsai, S. M.; Neves, M. C. P. Microbiologia do solo. Campinas: Sociedade Brasileira de Ciência do Solo, 1992. p.1-15.

Büll, L. T. Nutrição mineral do milho. In: Bull, L. T.; Cantarella, H. (ed). Cultura do milho: fatores que afetam a produtividade. Piracicaba: Potafos, 1993. p.63-131.

Coelho, F. S.; Verlengia, F. Fertilidade do solo. 2.ed. Campinas: Instituto Campineiro de Ensino Agrícola, 1973. 384p.

CONAB - Companhia Nacional de Abastecimento. Acompanhamento da safra brasileira de grãos 2011/12, $8^{\circ}$ levantamento. http//www.conab.gov.br. 20 Mai. 2012.

Dobbelaere, S.; Croonenborghs, A.; Thys, A.; Ptacek, D.; Okon, Y.; Vanderleyden, J. Effect of inoculation with wild type Azospirillum brasilense and A. irakense strains on development and nitrogen uptake of spring wheat and grain maize. Biology and Fertility of Soils, v.36, p.284-297, 2002.

Döbereiner, J.; Baldani, I. J. Bases científicas para uma agricultura biológica. Ciência e Cultura, v.34, p.869-881, 1982.

Dotto, A. P.; Lana, M. do C.; Steiner, F.; Frandoloso, J. F. Produtividade do milho em resposta à inoculação com Herbaspirillum seropedicae sob diferentes níveis de nitrogênio. Revista Brasileira de Ciências Agrárias, v.5, p.376-382, 2010.

Duete, R. R. C.; Muraoka, T.; Silva, E. C. da; Trivelin, P. C. O.; Ambrosano, E. J. Manejo da adubação nitrogenada e utilização do Nitrogênio $(15 \mathrm{~N})$ pelo milho em Latossolo Vermelho. Revista Brasileira de Ciência do Solo, v.32, p.161-171, 2008.

Fancelli, A. L.; Dourado Neto, D. Produção de milho. Guaíba: Agropecuária, 2000. 360p.

Ferreira, D. F. Sisvar: Um programa para análises e ensino de estatística. Revista Symposium, v.6, p.36-41, 2008.

Gyaneshwar, P.; Kumar, G. N.; Parekh, L. J.; Poole, P. S. Role of soil microorganisms in improving P nutrition of plants. Plant Soil, v.245, p.83-93, 2002.

Gray, E. J.; Smith, D. L. Intracellular and extracellular PGPR: commonalities and distinctions in the plant-bacterium signaling processes. Soil Biology and Biochemistry, v.37, p.395-412, 2005.

Hungria, M.; Campo, R. J.; Souza, E. M.; Pedrosa, F. O. Inoculation with selected strains of Azospirillum brasilense and A. lipoferum improves yields of maize and wheat in Brazil. Plant Soil, v.331, p.413-425, 2010.

Iniguez, A. L.; Dong, Y.; Triplett, E. W. Nitrogen fixation in wheat provided by Klebsiella pneumoniae 342. Molecular Plant-Microbe Interactions, v.17, p.1078-1085, 2004. 
Lana, M. do C.; Dartora, J.; Marini, D.; Hann, J. E. H. Inoculation with Azospirillum, associated with nitrogen fertilization in maize. Revista Ceres, v.59, p.399-405, 2012.

Lucena, L. de F. C.; Oliveira, F. A. de; Silva, I. de F. da; Andrade, A. P. de. Resposta do milho a diferentes dosagens de nitrogênio e fósforo aplicados ao solo. Revista Brasileira de Engenharia Agrícola e Ambiental, v.4, p.334-337, 2000.

Marschner, H. Mineral nutrition of higher plants. San Diego: Academic Press, 1995. 889p

Moreira, F. M. de S.; Silva, K. da; Nóbrega, R. S. A.; Carvalho, F. de. Bactérias diazotróficas associativas: Diversidade, ecologia e potencial de aplicações. Comunicata Scientiae, v.1, p.74-99, 2010.

Okon, Y.; Labandera-Gonzalez, C. Agronomic application of Azospirillum: An evaluation of 20 years worldwide field incubation. Soil Biology and Biochemistry, v.26, p.15911601, 1994.
Olivares, F.L. Taxonomia, ecologia e mecanismos envolvidos na infecção e colonização de plantas de cana de açúcar (Saccharum sp. híbrido) por bactérias diazotróficas endofíticas do gênero Herbaspirillum. Seropédica: UFRRJ, 1997. 344p. Tese Doutorado

Quadros, P. D. de. Inoculação de Azospirillum spp. em sementes de genótipos de milho cultivados no Rio Grande do Sul. Porto Alegre: UFRGS, 2009. 62p. Dissertação Mestrado

Radwan, T. E. E.; Mohamed, Z. K.; Reis, V. M. Efeito da inoculação de Azospirillum e Herbaspirillum na produção de compostos indólicos em plântulas de milho e arroz. Pesquisa Agropecuária Brasileira, v.39, p.987-994, 2004.

Rao, A. C. S.; Smith, J. L.; Parr, J. F.; Papendick, R. I. Considerations in estimating nitrogen recovery efficiency by the difference and isotopic dilution methods. Fertilizer Research, v.33, p.209-217, 1992.

Reis, V. M.; Baldani, J. I.; Baldani, V. L.; Döbereiner, J. Biological dinitrogen fixation in gramineae and palm trees. Critical Reviews in Plant Sciences, v.19, p.227-247, 2000. 